\title{
¿Hacia dónde va la historiografía norteamericana?
}

Entrevista realizada por los integrantes del Proyecto de Historia de los Estados Unidos al Dr. John Coatsworth, el siete de septiembre de 1984, en México, Distrito Federal.

John $\mathrm{H}$. Coatsworth ha impartido diversos cursos en importantes centros de investigación sobre temas relacionados con la historia social y económica de México, Latinoamérica y los Estados Unidos. Es autor de numerosos artículos sobre distintos aspectos de su especialidad, publicados en las principales revistas de investigación social mexicanas y norteamericanas. Recientemente. Editorial Era reimprimió su obra El impacto social de los ferrocarriles durante el porfiriato. (SepSetentas 1976). Su nuevo libro: From back wardness to Underdevelopment: The mexican economy, sobre historia económica de México desde finales de la colonia hasta las postrimerias de la época porfirista, está en proceso de edición en El Colegio de México. Actualmente es profesor en la Universidad de Chicago.

En los últimos años observamos cambios importantes en la historiografía norteamericana, las corrientes se han diversificado y han surgido nuevos enfoques como el de la nueva izquierda, ¿podría mencionarnos las tendencias historiográficas más importantes de este siglo?

Tal vez podemos resumir las tendencias más importantes en la historiografía de los Estados Unidos en cuatro escuelas. La primera, que podemos llamar la escuela patriótica, empezó en el siglo pasado con Bancroft ${ }^{1}$ quien tiene estudios sobre México, Centroamérica y El Caribe. La segunda escuela, llamada progresista, de los años veinte y treinta, cuyo representante más importante fue Charles Beard. ${ }^{2}$ Tal vez la tercera escuela sería la escuela del consenso, y Daniel Boorstin ${ }^{3}$ sería su representante más interesante. Finalmente, lo que podemos llamar la escuela revisionista o de la "nueva izquierda" que empezó con William Appleman Williams ${ }^{4}$ y que tiene como representante de la tendencia marxista a Eugene Genovese. ${ }^{5}$

¿Cómo ubicaria usted la primera tendencia dentro del desarrollo histórico de los Estados Unidos y qué características tiene?

Bueno, la escuela patriótica tiene una historia muy larga. Bancroft empezó su carrera antes de la guerra civil, en los años cuarenta del siglo pasado.

1 George Bancroft, History of the colonization of the United States, Boston, Little Brown, 15 ed., 1854

- History of the United States of America from the discovery of the Continent, Chicago. University of Chicago Press, 1966.

2 Charles A. Beard, Historia de la civilización de los Estados Unidos de Norte América desde sus origenes hasta el presente, Buenos Aires, G. Frakft, 1946, 4 vols.

- Historia de los Estados Unidos, Buenos Aires. Depalma. 1962

- Una interpretación económica de la Constitución de los Estados Unidos, Buenos Aires. Arayú. 1953

3 Daniel J. Boorstin, The Americans: The Colonial Experience, Nueva York, Random, 1958.

- The Americans: The National Experience, Nueva York. Random. 1965.

- The Americans: The Democratic Experience, Nueva York. Random. 1973.

- Estados Unidos, una civilización. Barcelona. Labor, 1975.

- Historia de los Norteamericanos, Buenos Aires, Depalma, 1973

4 William A. Williams. Americans in a changing world: a history of the United States in the twentieth century, Nueva York, Harper \& Row. 1978.

- The Roots of the Modern American Empire, Nueva York, Random House, 1969.

- The Tragedy of American Diplomecy, Nueva York, Dell. 1972.

- Empire As a Way of Life: An essay on the Causes and Character of America's Present Predicament, along with a few Thoughts About an Alternative, Oxford, Oxford University Press, 1982.

5 Eugene D. Genovese, The Political Economy of Slavery, Nueva York, Random House, 1965.

- Roll, Jordan, Roll: The World the Slaves Made, Nueva York, Pantheon, 1974. 
Esta escuela la encontramos dentro de un movimiento cultural que surgió frente al problema de la nacionalidad. Querian crear un sentido de nacionalidad norteamericana. Tuvo mucho más importancia a finales del siglo pasado, frente a la llegada de millones de migrantes extranjeros. Entonces esta corriente fue profesionalizada con asociaciones de historiadores, con escuelas de graduados, etcétera. Aunque llegó a ser un poco más científica que Bancroft, los historiadores iniciales de esta escuela todavía siguieron tratando de definir lo que era la nacionalidad norteamericana. Un representante que podemos mencionar es Woodrow Wilson., ${ }^{6}$ quien fue presidente de los Estados Unidos durante la primera guerra mundial. Lo interesante de esta escuela es que representó un periodo en la historia de los Estados Unidos en el que casi todos los historiadores eran anglosajones. El gremio de los historiadores antes de la depresión mundial de los años treinta era muy cerrado: más bien era un grupo de la clase media o alta que trataba de convencer al resto del país de que había algo especial en la historia de la nación para legitimizar las instituciones, las ideas, la cultura, etcétera.

La segunda, la escuela "progresista" nació de la desilusión del periodo después de la primera guerra mundial; es aquí donde encontramos las primeras influencias del marxismo europeo en la academia. Esta escuela de Charles Beard, Becker ${ }^{7}$ y otros, resaltó la importancia de la historia económica y de los intereses económicos de clase en la historia del país. La obra maestra de Charles A. Beard es La Interpretación Económica de la Constitución. ${ }^{8}$ donde trata de mostrar que los representantes a la convención que hizo la constitución del país eran de la clase alta y lo que hicieron fue representar sus intereses; Beard trató de analizar la constitución como producto de una clase en vez de como producto de una idea de la nación surgida de la lucha patriótica por la independencia. Esta misma idea fue la interpretación básica de la escuela anterior.

La escuela del consenso es producto de una reacción en contra de los progresistas y surgió en la época de la guerra fría, después de la segunda guerra mundial. Esta escuela negó importancia a los conflictos en el pasado de los Estados Unidos, en contraste con la escuela progresista que trató de encontrar conflictos de clase y conflictos económicos en el pasado. La escuela del consenso negó importancia tanto a estos conflictos de interés. como a los conflictos políticos en el pasado del país. Por el contrario recalcó lo que unía a la nación en cada época de su historia. El problema más importante que tuvo esta escuela fue cómo interpretar la guerra civil del siglo XIX cuando evidentemente hubo un conflicto de gran importancia en el país. En este caso la escuela del consenso llegó a la confusión, superficialmente, de que la guerra civil no representó un conflicto profundo entre dos sociedades del norte y del sur, que no tuvo que ver con la esclavitud en sí, pero representó un fracaso del sistema político en manos de los líderes de aquél entonces $y$ que la guerra civil no fue inevitable, pero, por un fracaso eventual del sistema político, el pais cayó en este enfrentamiento innecesario para terminar con la esclavitud. Entonces, podemos calificarla como una escuela de celebración a la democracia burguesa del país. celebración del éxito de los refor-

6 Woodrow Wilson, Division and reunion 1828-1889, Nueva York y Londres, Longmans, Green and Co., 1893.

- A history of the American People. Nueva York, Harper \& Row, 1908, 5 vols.

7 Carl L. Becker. The Declaration of Independence: A Study in the History of Political Ideas, Nueva York. Random House, 1958

- The History of Political Parties in the Province of New York, 1760-1776, Madison. University of Wisconsin Press. 1960.

8 Véase la nota 2 
mistas en cada época, reformistas que trabajaban dentro del sistema político del país, en contraste con los radicales, los revolucionarios que trataban de cambiar fundamentalmente el país.

El surgimiento de una historiografía revisionista en los años sesenta res. ponde a una serie de cambios en la sociedad norteamericana ¿podría señalar cuáles son esos cambios?

Bueno, para empezar, sería útil esbozar un poco lo que fue o es la historiografía revisionista. Esta escuela empezó en plena guerra fría en el campo de la historia diplomática con los trabajos de William Appleman Williams ${ }^{9}$ y sus discipulos como Walter Lafeber ${ }^{10}$ y L. Gardner. ${ }^{11}$ Creció y se expandió a consecuencia de los movimientos políticos y sociales de los años sesenta y ahora esta escuela se encuentra en todos los campos de la investigación histórica del país. Las contribuciones más importantes que ha logrado se encuentran en primer lugar en la historia diplomática, en la historia de las relaciones exteriores. Williams fue el primer historiador después de la segunda guerra mundial que trató de reinterpretar los origenes de la guerra fría y más allá, los orígenes de la política exterior de los Estados Unidos en la época contemporánea. En los años sesenta el revisionismo se expandió para hacer contribuciones importantes a la historia de los grupos ignorados por la escuela del consenso: los pobres, los esclavos, las minorías, sobre todo los negros, pero también los chicanos, los hispanos, la historia de la mujer y, más recientemente, la historia obrera. Empezaron con la idea de hacer la historia desde abajo, desde las clases explotadas. También en el desarrollo de la escuela revisionista ha sido importante la influencia de la expansión del estudio de otras regiones del país y las conexiones o las relaciones entre historiadores norteamericanos que estudian los Estados Unidos e historiadores norteamericanos que trabajan otras regiones, sobre todo el tercer mundo. Lo que podemos decir del revisionismo es que no es una escuela bien definida, es una escuela muy variada en la cual destacan varias corrientes, desde el liberalismo social hasta el marxismo o neomarxismo. El surgimiento de esta escuela respondió a una serie de cambios socio-económicos y políticos en el pais. La nueva historia diplomática de Williams y sus seguidores respondió a las contradicciones evidentes en el papel que tomaron los Estados Unidos como superpotencia durante la posguerra, en la época de los años cincuenta. Esta tendencia fue nutrida por el pequeño movimiento para la paz nuclear que hubo desde entonces. Esta escuela expandió en los años sesenta la nueva historia diplomática por dos situaciones: una fue la revolución cubana que marcó un cambio muy importante en la historiografía del pais y otra, tal vez un poco más importante, fue la guerra en Vietnam.

La historia de las minorías fue en un sentido producto del movimiento para los derechos civiles de la población negra del país y de ahí, de la historia de los negros, se expandió al estudio de otros grupos explotados u olvidados por la historiografía tradicional. Esta tendencia tuvo un impacto muy importante en varias universidades del país, tal vez en la mayoría, donde se crearon centros de investigación de la historia de las minorías, de la mujer, etcetera.

En el desarrollo del revisionismo también fue importante la llegada a los Estados Unidos de varias influencias externas, sobre todo de Europa occi-

\footnotetext{
9 Véase la nota 4.

10 Walter Lafeber, The New Empire: An Interpretation of American Expansionism, 1869-1898, Ithaca. Cornell University Press, 1963.

"Lloyd C. Gardner. Economic Aspects of New Deal Diplomacy, Madison, University of Wisconsin Press, 1964.

- Looking Backward: A Reintroduction to American History, s.I., McGraw, 1974
} 
dental, especialmente de Gran Bretaña y Francia. La obra maestra de E. P. Thompson, ${ }^{12}$ por ejemplo, tuvo un impacto enorme en la historiografía de Estados Unidos, alentando el estudio de la historia social y dando un enfoque más sofisticado de los grupos explotados, de los inmigrantes, de las minorias. También de esos dos países llegó a Estados Unidos el marxismo. pero un marxismo muy diferente al que los historiadores habían encontrado antes, el neomarxismo y una serie de corrientes nuevas. En esa época de los años sesenta hubo varias coincidencias importantes que contribuyeron a explicar el desarrollo del revisionismo. Esta coincidencia fue la guerra en Vietnam y el movimiento para los derechos civiles de la población negra, por una parte, y por la otra, una expansión sin precedentes en el sistema de educación superior en el país; es decir, se duplicaron en pocos años la población universitaria y el número de profesores también tuvo que incrementarse rápidamente. Otra coincidencia fue el impulso que dio en aquel entonces el gobierno federal no sólo a la expansión en general del sistema de educación superior, sino también a la expansión de los estudios internacionales. El gobierno estimuló la investigación de otras regiones del mundo, sobre todo del tercer mundo, porque se dio cuenta durante la guerra en Vietnam de que no había expertos en asuntos del sureste asiático, casi nadie hablaba vietnamita; entonces trató de expandir los estudios internacionales en las universidades del país. Esto alentó el revisionismo en la historiografía de los Estados Unidos por los contactos entre los nuevos historiadores y científicos sociales, estudiosos del tercer mundo y abiertos a las influencias ideológicas de estas regiones por un lado, y los historiadores de los Estados Unidos por el otro.

\section{¿Considera usted que se puede hablar de una tendencia historiográfica dominante en este momento?}

Yo creo que no. Podemos hablar de lo que Gramsci calificó como guerras de posición en cada campo de la historia de la ciencia social. La característica dominante de la historiografía norteamericana ahora es la variedad, la competencia de ideas y de teorias, no hay escuela dominante. En cada campo de la investigación histórica hay obras de diferentes corrientes y en algunos casos podemos decir que la influencia de la "nueva izquierda" o del revisionismo es por el momento dominante, pero en otro campo, en otro periodo, en otra región no lo es. Entonces lo que caracteriza la historiografía de los Estados Unidos, tal vez por primera vez en su historia - la excepción sería los años treinta - es la competencia, la variedad.

Después de este análisis ¿cuáles son las perspectivas para el desarrollo historiográfico de la nueva izquierda?

Pues por el momento creo que esta tendencia tiene buenas perspectivas: al mismo tiempo es necesario reconocer la importancia de la relación entre la historiografía por un lado y la sociedad por el otro. La elección de un presidente conservador ha tenido un impacto alentador para la derecha, para la ola derecha de la historiografía estadunidense. Yo creo que el futuro de la historiografía revisionista, o más bien historiografía izquierdista en el sentido amplio, va a depender de las tendencias políticas y sociales del país fuera de la academia más que de las de adentro. Por el momento tiene buenas perspectivas. Tiene un impacto muy importante en el mundo intelectual y académico de los Estado Unidos pero hay que tomar en cuenta las tendencias fuera de la academia; la lucha de clases, la lucha política, las tendencias en general en el país.

12 E. P. Thompson, La formación histórica de la clase obrera en Inglaterra: 1780-1832. Barcelona. Laia, 1977 
¿Se podria decir que la tendencia historiográfica de la "nueva izquierda"forma parte de un proyecto de transformación de la sociedad norteamericana?

Pues tal vez: en un sentido, la historiografía de la izquierda siempre ha estado ligada a los movimientos sociales, a los movimientos para la transformación del país, pero no podemos decir que esta corriente historiográfica esté ligada a un proyecto en particular sino a los muchos proyectos que han surgido de los movimientos populares de los años sesenta y después. Esta corriente contiene posiciones que van desde el liberalismo social, el socialismo. la democracia social y muchas variedades del marxismo. Lo que les une es una visión de un país con más justicia social y menos agresión en el exterior, etcétera. Existen divergencias muy importantes dentro de esta corriente, o sea hay muchos proyectos de transformación del país; cada historiador tiene el suyo y esta corriente no está lígada a ningún partido político porque no hay partido político de la izquierda en Estados Unidos, ni está ligada al movimiento obrero tal como es, porque éste tiene ahora un liderazgo bastante conservador, sobre todo en cuanto a política exterior. Sí podemos decir que esta corriente históriográfica tiene relación con los movimientos sociales para la transformación, en primer lugar para el progreso social dentro del sistema que tenemos y en segundo, para varios proyectos de transformación más profunda que han surgido de estos movimientos sociales, pero no está ligada a un proyecto en particular; es una corriente abierta a varias ideas, a varios proyectos de transformación para el futuro del país. 